\title{
UM ESBOÇO DE ANÁLISE LITERÁRIA BASEADA EM CONHECIMENTO PROPOSICIONAL: “EPITAPH ON A TYRANT”, W. H. AUDEN
}

\begin{abstract}
Fabiano Seixas Fernandes é professor de Literatura de língua inglesa pelo Departamento de Letras Estrangeiras—Centro de Humanidades, UFC.

E-mail: fbnfnds@gmail.com
\end{abstract}

Resumo: O presente artigo esboça um modelo de análise de textos literários baseado na noção de conhecimento proposicional, tendo em vista a discussão de questões pertinentes tanto à filosofia da literatura quanto à crítica literária, quais sejam: qual a relação entre literatura e conhecimento? A literatura produz ou veicula conhecimento? Se sim, de que modos? Suas características epistemológicas poderiam ser instrumentais em nos auxiliar a definir ou analisar literatura? O poema "Epitaph on a Tyrant", do poeta W. H. Auden, foi selecionado a esmo e analisado, na tentativa de abordar essas questões.

\begin{abstract}
The present article sketches a model of literary analysis based on the concept of propositional knowledge, with the intent to tackle some issues relevant to both Philosophy of Literature and Literary Criticism: What is the relation between literature and knowledge? Can literature produce or publicize knowledge? If so, how? Are its epistemic features instrumental to the analysis of literary texts, or in defining Literature? In order to approach these questions, the poem "Epitaph on a Tyrant" by W. H. Auden was randomly selected and analyzed.
\end{abstract}

É um fato de nossa vida acadêmica e de nosso senso comum que agregamos valor epistêmico ao conjunto de textos a que chamamos literatura, bem como ao conjunto de práticas que leva à sua produção e leitura. Se for verdade que a literatura produz ou veicula conhecimento - seja novo ou antigo, banal, ou semelhante ao científico - então deveria haver algum modo de se analisá-la e avaliá-la com base nesse conhecimento, independentemente de essa característica ser essencial para a definição de literatura, ou de o conhecimento que produz ou veicula the ser exclusivo.

O presente artigo intenta dar alguns passos na direção de desenvolver um método de análise literária baseado em sua relação com o conhecimento. Inicialmente, concentrar-me-ei no conhecimento dito proposicional, uma vez que se trata do tipo mais estudado (o que provavelmente se deve ao fato de que, como permite transcrição lingüística, é o mais fácil de ser apreendido). Selecionei a esmo um curto poema de W. H. Auden, "Epitaph on a Tyrant", e busquei desmontar sua estrutura proposicional, separando o que nesse poema poderia ser considerado conhecimento banal (mera reprodução do já conhecido) do novo. No caso do conhecimento banal, há a possibilidade de ele ser problematizado pelo texto literário - o que demonstraria menos adesão ao senso comum (popular ou científico) e maior senso crítico; no caso do conhecimento novo, há a possibilidade de ele ser gerado de forma a assemelhar-se a conhecimento adquirido cientificamente; essas possibilidades também fazem parte de nossa investigação aqui levada a termo ${ }^{i}$. 
Adicionalmente, esse esboço de um método conteudístico de análise literária nos permitirá tanger temas mais amplos da epistemologia do objeto literário, tais como: a literatura é capaz de produzir conhecimento original, semelhante ao científico? Se o faz, lança mão de metodologia própria, ou empresta métodos à ciência e à filosofia? Haveria conhecimentos que somente a literatura é capaz de produzir, ou ao menos que são mais eficazmente produzidos por vias literárias que por vias científicas? Essas questões de caráter mais amplo aproximam-se gradativamente de outra, diretamente relacionada ao labor do crítico literário: de que modo a relação entre literatura e conhecimento (proposicional ou outro) nos auxilia a definir literatura e a valorar obras literárias? ${ }^{\mathrm{ii}}$

\section{Análise proposicional de "Epitaph on a Tyrant"}

Epitaph on a Tyrant

W. H. Auden

Perfection, of a kind, was what he was after,

And the poetry he invented was easy to understand;

He knew human folly like the back of his hand,

And was greatly interested in armies and fleets;

When he laughed, respectable senators burst with laughter,

And when he cried the little children died in the streets ${ }^{\text {iii }}$.

Sendo o conhecimento proposicional aquele que pode ser transcrito por meio de sentenças declarativas, passíveis de se lhes atribuir valor de verdade, o poema de Auden faz com que nossa tarefa não pareça, em princípio, difícil: todo o poema é composto por sentenças declarativas afirmativas. Não teríamos senão que verificar o valor de verdade dessas asserções para agregarmos maior ou menor valor epistêmico ao poema.

Levanta-se logo, porém, um primeiro problema, apontado por John Searle. Se digo que meu irmão mais novo tem 30 anos, isso será verdade se e somente se houver no mundo um ser real que seja meu irmão e tenha 30 anos; se o narrador de um romance disser que seu irmão mais novo tem 30 anos, não esperamos que exista alguém no mundo que corresponda a essa descrição, tampouco consideramos que esteja mentido. Estaríamos diante de uma declaração afirmativa que não se comporta como uma declaração afirmativa: não é nem verdadeira nem falsa, pois, curiosamente liberada das exigências referenciais que guiam nossas práticas lingüísticas quotidianas, não se espera dela que corresponda a estado algum no mundo. Ao analisar esse impasse, Searle chega a quatro conclusões:

[1] [T]he author of a work of fiction pretends to perform a series of illocutionary acts, normally of the representative type.

[2] [T] he identifying criterion to whether or not a text is a work of fiction must of necessity lie in the illocutionary intentions of the author.

[3] [T] he pretended illocutions which constitute a work of fiction are made possible by the existence of a set of conventions which suspend the normal operation of the rules relating illocutionary acts and the world. 
[4] [T] he pretended performance of illocutionary acts which constitute the writing of a work of fiction consist in actually performing utterance acts with the intention of invoking the horizontal conventions that suspend the normal illocutionary commitments of the utterances ${ }^{\text {iv }}$. (JoHn \& Lopes: 2004, pp.114-5. Grifos meus.)

Para Searle, como se vê, o ato de fala do escritor é um ato fingido, que simula produzir sentenças semelhantes às que encontramos no dia-a-dia, mas que não operam pelas mesmas regras no tangente ao valor de verdade. Assim, o primeiro impasse teórico em nossa análise do poema de Auden estaria em determinar onde estariam as proposições candidatas a verdade em uma obra de ficção, já que não se pode atribuir valor de verdade a seus enunciados.

Searle resolveu o problema semântico que apontou referindo-o à teoria de atos de fala: a chave para a anomalia do discurso literário estaria na intenção de seu autor de que seja tratado como ficção. Do modo como entendo o problema epistemológico que apontei (como pode haver conhecimento em literatura se não há referência externa ? $^{\mathrm{v}}$ ), é possível lhe esboçar uma solução composta por duas etapas. A primeira está nas máximas cooperativas de Paul Grice. Segundo Grice, um dos princípios que regem a comunicação quotidiana, via de regra, é a pressuposição de que nossos interlocutores, ao planejar suas falas, regem-se por determinadas máximas, quais sejam:

- Qualidade: diga a verdade.

- Quantidade: diga apenas o necessário para ser compreendido.

- Relação: seja relevante.

- Clareza: evite ambigüidades.

Das quatro, a máxima de relevância parece ser a mais importante, e por vezes parece englobar as demais: mentiras, hermetismo, laconismo e informações supérfluas dificilmente seriam considerados relevantes em qualquer comunicação. Seja como for, devemos lembrar que essas máximas não são leis; parece bastante óbvio que não é possível cumprir todos esses quesitos todo o tempo. O que realmente importa é que nossa interpretação de atos de fala alheios pressupõe que nossos interlocutores estão ao menos tentando. (Por exemplo: posso supor que um palestrante prolixo está se esforçando por ser claro; que alguém a quem pedi uma informação, mas que não a consegue dar prontamente está se esforçando por dizer a verdade.) É esse pressuposto interpretativo que nos faz inferir que certos enunciados que aparentem romper alguma das máximas estejam, na verdade, seguindo-as: é o evidente caso do discurso literário, que não raro rompe com a máxima de clareza e que, a julgar pelo problema apontado por Grice, também teria problemas com a de qualidade. Assim, se desejamos mesmo continuar acreditando no valor epistêmico da literatura, temos de supor que suas "verdades" não seriam encontradas em nível literal. Deve haver algum caminho indireto referendando ficção ao mundo.

Quanto à segunda etapa da solução: a partir do momento que supomos que, se há verdade (ou proposições candidatas a verdade) no discurso literário, não deve ser buscada (somente) em nível literal, é necessário saber como inferi-la. Supus em princípio haver algum caminho indireto. A meu ver, as práticas de escrita indireta literária são, em verdade, muito 
variadas. Em certo sentido, a escrita literária é uma escrita de desvios; cada desvio, mais que um prolongamento, é também uma estação de chegada - posso seguir adiante, mas posso também parar por aqui ${ }^{\mathrm{vi}}$.

Ao invés de fornecer exemplos concretos desse tipo de escrita indireta, penso ser mais producente verificar quais surgiriam em nosso estudo do poema de Auden. Passemos, então, a ele: como foi dito anteriormente, o poema é composto quase exclusivamente por enunciados declarativos afirmativos; para destacar ainda mais seu conteúdo proposicional literal, poderíamos parafraseá-los da seguinte forma:

(01) (Ele) buscava a perfeição.

(02) A poesia que (ele) inventou é de fácil compreensão.

(03) (pressuposto de 02) (Ele) inventou poesia.

(04) (Ele) conhecia muito bem a tolice humana.

(05) (Ele) se interessava muito por exércitos e frotas.

(06) Se (ele) ria, então os senadores gargalhavam.

(07) (pressuposto de 06 $6^{\text {vii }}$ ) Às vezes (ele) ria.

(08) Se (ele) chorava, então as crianças morriam.

(09) (pressuposto de 08) Às vezes (ele) chorava.

O poema, como se vê, é composto por predicados referentes a um único sujeito - um suposto "ele", expresso gramaticalmente em inglês desde a primeira linha do poema. Quem seria "ele"? O título nos informa que se trata de um epitáfio - ou seja, pela análise de Searle, o autor finge realizar o ato ilocucionário de escrever um epitáfio. Sendo o epitáfio a "um" tirano, conseguimos inferir duas novas informações acerca d"ele":

(10) Ele é um tirano.

(11) Ele está morto.

Isso justificaria o uso do pretérito imperfeito na tradução da maioria dos verbos: buscava, conhecia, interessava-se, ria, chorava. O poema não narra os feitos do tirano; descreve-o através de preferências, objetivos, entre outros.

Aproximamo-nos agora de uma possível solução para o problema de inferir a "verdade" da literatura. Apesar de não ser necessário que o tirano de que fala Auden haja existido, todos conhecemos ou já ouvimos falar de tiranos - ou seja, ao tratar de tiranos, o poema reproduz conhecimento banal. Sendo esse tirano composto a partir do que são os tiranos, a relação pode se inverter, permitindo que "Epitaph on a Tyrant" seja encarado como um poema sobre tiranos em geral: o tirano de Auden simbolizaria o conjunto dos tiranos; as proposições acerca dele - indiferentes ao valor de verdade que assumiriam frente a um possível referente externo, devido ao fingimento típico do autor literário - assumem, assim, valor de verdade se pensadas como proposições acerca de uma classe de indivíduos, os tiranos. Isso está de acordo com o que acima chamei de escrita indireta literária: fala-se de como era um tirano para dizer como são os tiranos. Assim, um dos modos de solucionar o problema da verdade literária estaria no que chamo (talvez provisoriamente) de referência 
hiperbólica: em literatura, seres individuais se tornam símbolos do(s) conjunto(s) ao(s) qual(is) pertencem ${ }^{\text {viii. }}$.

Se aceitarmos o mecanismo da referência hiperbólica, então se torna mais simples verificar que o poema é (em parte) composto por algumas informações banais às quais simplesmente aceita: a de que os tiranos morrem, a de que os tiranos, sendo chefes de estado, têm algum tipo de relação com o exército e com o Senado. É essa rede inferencial ligando indiretamente o poema ao mundo que nos leva, por exemplo, a não estranhamos que receba um epitáfio, ou seu interesse por "exércitos e frotas".

A partir daqui, contudo, as coisas ficam mais difíceis. Se, por um lado, o poema reproduz conhecimento, por outro estabelece algumas relações novas, incomuns. Tratar-se-ia acaso de conhecimento novo, ou ao menos da problematização de conhecimento banal? Vejamos:

(01) ...buscava a perfeição.

(03) ....inventou poesia.

(04) ...conhecia a tolice humana.

(05) ....interessava-se por exércitos.

(06) Se (ele) ria, então os senadores gargalhavam.

(08) Se (ele) chorava, então as crianças morriam.

Os predicados desse tirano incógnito (estendidos, pela referência hiperbólica, ao conjunto dos tiranos) relacionam-no a coisas que normalmente não associaríamos a tiranos. Qualquer ser humano poderia ser sujeito desses predicados, verdade, mas o que nos interessa aqui é que Auden não se limita a acionar nosso conhecimento acerca do que é comum entre os tiranos. Estaria propondo algo novo? Aparentemente, sim, mas, olhando mais de perto, vemos que pode não ser bem o caso.

Comecemos pelo usual: em primeiro lugar, as relações causais estabelecidas por (06) e (08) não parecem destoar do que se esperaria de um tirano. Tendo poder absoluto, um tirano é uma lei em si mesmo; isso torna viável que seus estados de espírito tenham impacto direto nas decisões do governo e no bem-estar dos cidadãos. Estabelece-se, contudo, uma espécie de inflação causal: a conseqüência é mais intensa que a causa; o riso gera gargalhada, o choro gera morte. Não obstante a força que as imagens escolhidas por Auden possam ter em diferentes leitores, nada há de particularmente inédito nisso. Em segundo lugar, o pouco surpreendente "interesse" do tirano por exércitos parece, contudo, romper a máxima griceana de quantidade: como chefe de estado, um tirano tem poder sobre o exército; seu "interesse" ou "desinteresse" implicariam maior ou menor uso da força armada em sua administração. Nosso conhecimento da tirania nos diz que não costuma ser pacífica; assim, esse "interesse" é eufemístico; (05) pode ser reescrita do seguinte modo:

(05') Ele (o tirano) faz amplo uso de exércitos e frotas (de força armada).

Haverá outros eufemismos nos demais predicados? Voltemo-nos agora aos itens destoantes. Analisemos, portanto, perfeição e poesia. O que significaria para um tirano "buscar a perfeição"? Se definirmos perfeição como sendo "a ausência de falhas, deficiências, 
defeitos e problemas", e sendo um tirano um governante, o mais natural é inferirmos que seu ideal de perfeição seja gerencial: uma certa configuração administrativa e social, à qual buscaria alcançar - por exemplo, através do poder armado. Além disso, a perfeição é estável: o perfeito dispensa e mesmo repele mudanças. Nosso tirano poderia estar buscando, portanto, a estabilidade: um país onde tudo ocorra sem surpresas, sem imprevistos, e sobre o qual seu poder estaria assegurado. E quanto à sua poesia? Sendo a poesia uma composição escrita, poderia ser outro eufemismo para essa mesma situação - vista agora como uma ordem à qual concebeu e cuja configuração talvez tenha (para ele) propriedades estéticas. Também, como a poesia é fruto da atividade intelectual, poderia representar seu plano administrativo, calcado na obediência acrítica - afinal, nada mais simples que obedecer sem questionar, e nada mais afim à mente de um tirano.

Como se vê, as estranhezas em nível literal puderam ser resolvidas inferencialmente; essas inferências retornam a nosso conhecimento prévio acerca do que seja um tirano. É importante, porém, atentarmos para o fato de que, sendo inferências, não são exclusivas: algo que os tiranos fazem é semelhante à poesia; algo do que buscam é semelhante à perfeição; a rigor, não sabemos o que exatamente, e o poema não nos dá suficientes pistas para termos certeza absoluta acerca de qualquer tentativa de resolução. Outras possibilidades poderiam ocorrer; não é mesmo impossível que algum leitor conseguisse encontrar um modo de enquadrar poesia e perfeição no poema sem lhes reduzir a algo tipicamente tirânico. Parte da riqueza cognitiva literária (e do problema em valorá-la epistemicamente) se encontra justamente em convidar a processos inferenciais sem lhes fornecer resposta definitiva; o texto se enriquece pelo acúmulo de atos distintos de interpretação, que não se cancelam nem mesmo quando se excluem mutuamente.

Embora minhas inferências só me permitam afirmar que Auden rompe as máximas griceanas de cooperação, forçando-nos a retornar ao que já sabemos, e que, portanto, não haveria conhecimento novo no poema, disso não se segue que o problema não consiga ao menos problematizar nosso conhecimento comum acerca dos tiranos. Problematizar não é sinônimo de propor; não é necessário dizer algo novo para se questionar algo antigo. $\mathrm{O}$ poema de Auden gera, sim, estranhamento, e, por um momento ao menos, obriga-nos a suspender nosso julgamento acerca de como acreditamos serem os tiranos.

\section{Exclusividade, valor epistêmico e definição de literatura}

O método que escolhemos para testar nossas proposições e perguntas a partir de um exemplo concreto nos leva somente até aqui. Não obstante, o trabalho do crítico literário não está concluído; para o crítico interessado em literatura do ponto de vista epistêmico, há ainda mais uma pergunta que necessita de resposta: qual a relação entre valor epistêmico e valor literário?

As soluções elencadas no início ao problema da relação entre literatura e conhecimento - a literatura pode reproduzir, divulgar, problematizar e produzir conhecimento 
- poderiam ser distribuídas ao longo de uma escala de valores: um texto que repete algo banal tem menor valor que outro que repete algo por ter ciência de que é importante; o repetidor consciente, menor o que problematizador; o problematizador, menor que o produtor. Para o crítico literário, resta saber se essa escala poderia ser traduzida diretamente em uma escala de valor estético-literário: o texto que repete o banal seria literariamente inferior ao que repete algo conscientemente? O repetidor, inferior ao problematizador? etc. Sendo ambas as escalas diretamente proporcionais, seria seguro inferir que valor epistêmico é parte importante do valor literário.

Embora não seja impossível que isso ocorra, não é necessária tanta uniformidade. Reduzir o literário ao meramente epistêmico não explicaria, por exemplo, o grande apelo de formas como o soneto - cuja elaboração formal cuidadosa muitas vezes manipula matéria banal. Não seria difícil multiplicar exemplos de textos literários que versam sobre algo trivial, e que não obstante retiveram a atenção de gerações de leitores e críticos.

Para retornar a nosso exemplo, outras coisas há no poema de Auden para além de dados corriqueiros acerca dos tiranos, ou do convite inferencial à sua redescoberta. Sendo o texto literário um texto no qual a produção de sentido está otimizada - ou seja, um texto que busca disponibilizar ou acionar o máximo de sentidos com um mínimo de recursos, a prática de leitura literária pode levar em consideração mais elementos que nossas paráfrases revelaram. Podemos não só traduzir o texto proposicionalmente, mas também nos questionarmos acerca das relações entre proposições: por que um uso tão baixo de conectores? Cada verso está praticamente isolado em si, e o único conector entre versos é meramente justapositivo: a conjunção aditiva and. Podemos não só recuperar inferencialmente alguns dados implícitos (foi o caso de [10] e [11]), mas também ler o fato mesmo de que não hajam sido explicitados. Por que o homem a quem o texto foi dedicado não é nomeado? Por que o texto usa eufemismos? Finalmente, podemos não só reconhecer que tipo de ato ilocucionário o autor finge realizar, mas também inquirir acerca dessa escolha. Por que simular um epitáfio? Por que não outro gênero textual?

Segundo me parece, essas perguntas levam a um mesmo rumo. Um epitáfio é uma espécie de homenagem: uma homenagem póstuma, a ser escrita no túmulo de alguém. Em inglês, um epitáfio pode ser para (for) alguém ou sobre (on) alguém. Auden escolhe on; a elipse acerca de quem seria esse tirano parece acionar a ambigüidade da preposição: o epitáfio é sobre (acerca d)o tirano, mas também está sobre (em cima d)ele. Repare que essa ambigüidade parece menos viável em outro poema-epitáfio:

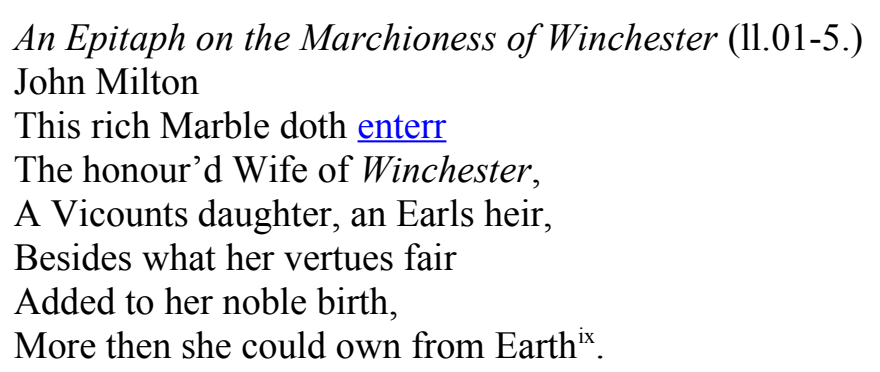


Parece mais evidente que se trata de uma homenagem - para isso concorre não só a explicitação da homenageada, mas a explicitação direta de seus atributos elogiáveis (honra, virtude, riqueza e nobreza). Repare que fica mais difícil ser igualmente elogioso no caso de um governante descrito como "tirano"; o poema de Auden, portanto, recorreria inicialmente à elipse e ao eufemismo como modos de dar aparência de homenagem. Conforme o poema progride, as relações se tornam mais explícitas, até chegarmos ao violento verso final. "Epitaph on a Tyrant", portanto, funciona como uma espécie de revelação progressiva, que começa pelo segredo e culmina na denúncia.

Essa explicação acima ainda não dá conta de explicar para que tanto segredo se o tirano está morto. Por que fingir homenageá-lo ao invés de denunciá-lo abertamente? Minha resposta para isso, novamente, une valor epistêmico e valor literário. $\mathrm{O}$ conhecimento dito proposicional, do qual nos ocupamos durante a análise, é apenas um dos tipos possíveis de conhecimento; há pelo menos outro, relacionado ao que vivenciamos - à nossa experiência direta e intransferível das coisas. A atmosfera de eufemismos e segredos, de fatos desconexos, da percepção de uma realidade atroz nunca diretamente mencionada é justamente a atmosfera comunicativa de um regime totalitário. O poema, escrito como se testemunhasse o fim de uma era de governo despótico, reproduz um aspecto da experiência de se estar sob semelhante governo. Temos, portanto, uma nova resposta à relação entre literatura e conhecimento, dessa vez uma resposta não-proposicional: a literatura se relaciona com o conhecimento na medida em que simula a experiência direta da realidade.

Essa resposta pareceria, em princípio, não só mais artística, mas também (ao contrário de nossa tentativa com o conhecimento proposicional) mais apta a responder o problema da exclusividade epistêmica em literatura. A ciência busca o conhecimento formal, consciente e organizado; a arte, por sua vez, sem necessariamente prescindir da descrição formal ou contradizê-la, pode também simular uma vivência. A descrição física ou molecular da água não aciona em nós a sensação de entrar em contato com a água, mas uma música, uma pintura, um poema ou mesmo uma dança podem sugerir e simular em nós algum aspecto de nossa experiência do que é a água ${ }^{\mathrm{x}}$.

Se aceitarmos a literatura como vivência simulada da realidade, talvez nos aproximemos de encontrar procedimentos epistêmicos exclusivamente literários. Antes disso, porém, teríamos de provar que todos os textos literários são compatíveis com essa visão; a crítica do conceito de arte como imitação já está feita ${ }^{x i}$, e penso não necessitar discutir o assunto novamente para vermos que essa nova proposta não é mais universal que as que lidaram com conhecimento proposicional.

Assim, nossa reflexão chega ao fim sem provar que a literatura é uma forma de conhecimento própria, que gera um tipo de conhecimento não compartilhado por outros gêneros; ao mesmo tempo, aponta alguns dos caminhos pelos quais passamos em nosso processo de leitura interpretativa, que justificariam a intuição de que a literatura está relacionada à busca pelo conhecimento, e que tornam difícil negar-lhe qualquer valor 
epistêmico. A grande dificuldade apontada por nosso percurso reside no fato de que asserções estritamente literárias (ou seja, aquelas pertencentes ao texto literário em nível literal) não têm valor de verdade referencial - não podem, portanto, ser conhecimento acerca do mundo. Não obstante, a literatura lança mão de inúmeros recursos que desencadeiam processos inferenciais, e é através desses processos que chegamos a conhecer ou a problematizar o que julgamos conhecer através da leitura de obras ficcionais. Independentemente, porém, da riqueza e variedade dessas inferências, de sua plausibilidade ou de seu grau de unanimidade junto a público e crítica, sendo inferências, não são fruto direto e inequívoco do texto literário. 
${ }^{i}$ Apesar de me parecer que a tipologia do conhecimento que esbocei é intuitivamente compreensível, estou ciente de que apresenta problemas formais: primeiramente, há o fato de que as categorias se entrecruzam: conhecimento científico ou cientificamente validado pode ser antigo ou banal (por exemplo, a lei da gravidade em sua forma quotidiana "tudo o que sobe, tem que descer"). Um segundo problema mais particular diz respeito à novidade: conhecimento novo para quem? Quanto ao primeiro, a simplicidade intuitiva das categorias facilita a percepção de quando devam ser combinadas, e quais as combinações possíveis; quanto ao segundo, novidade deve ser encarada não individual, mas coletivamente: é "novo" o conhecimento que, até então, não estava amplamente disponível para uma determinada comunidade - digamos, já que tratamos de literatura, para o conjunto dos leitores cultos.

${ }^{\text {ii }}$ A distinção entre conhecimento banal, novo e cientifico, a distinção entre reprodução, problematização e produção de conhecimento e as perguntas acerca dos métodos de produção literária de conhecimento e da exclusividade conteudística elou metodológica da literatura fazem parte de um esquema inicial da relação entre literatura e conhecimento, por mim apresentado durante o II FLAEL como parte da mesa-redonda "Letramento, discurso literário e ensino". O presente artigo visa retomar e testar esse esboço esquemático a partir de um exemplo concreto.

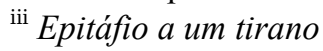

Alcançar a perfeição, de certo modo, é o que buscava,

E a poesia que inventou é de fácil compreensão;

Conhecia a tolice humana como a palma da mão,

E deveras lhe interessavam exércitos e frotas;

Quando ria, o mui respeitável senado gargalhava,

Quando chorava, crianças às ruas tombavam mortas. (Minha tradução.)

iv [1] O autor de uma obra ficcional finge realizar uma série de atos ilocucionários, normalmente de tipo representativo. [2] O critério que nos permite identificar se um texto é uma obra ficcional deve necessariamente ser buscado nas intenções ilocucionárias do autor. [3] As ilocuções fingidas que constituem uma obra ficcional tornam-se possíveis graças à existência de um conjunto de convenções [horizontais] que suspendem o funcionamento normal das regras [verticais] que relacionam atos ilocucionários e o mundo. [4] A performance fingida de atos ilocucionários que constitui a escrita de uma obra ficcional consiste em realizar verdadeiramente atos de fala com a intenção de invocar as convenções horizontais que suspendem os compromissos ilocucionários normais dessas falas. (Minha tradução.)

${ }^{v}$ Digo externa, pois é evidente que os textos literários geram referentes internos com os quais passam a trabalhar. Qualquer personagem de ficção, uma vez mencionado em uma obra literária, passa a ser referente para todas as suas menções futuras - daí, inclusive, como também aponta Searle, que afirmações externas ao texto literário sobre essa personagem sejam passíveis de se lhes atribuir valor de verdade (é falso que o Romeu da tragédia shakespeariana haja casado com Rosaline, por exemplo, e verdadeiro que haja sido banido para Mântua).

vi Ofereço um exemplo: "A sala do dentista tinha já algumas freguesas. Mariana [...] foi para a janela. Da janela podia gozar a rua, sem atropelo. Recostou-se; Sofia veio ter com ela. Alguns chapéus masculinos, parados, começaram a fitálas; outros, passando, faziam a mesma cousa. Mariana aborreceu-se da insistência; mas, notando que fitavam principalmente a amiga, dissolveu-se-lhe o tédio numa espécie de inveja. Sofia, entretanto, contava-lhe a história de alguns chapéus,—ou, mais corretamente, as aventuras. [...] Mariana ouvia aturdida. Na verdade, o chapéu era bonito, trazia uma linda gravata, e possuía um ar entre elegante e pelintra, mas..." (Machado de Assis: "Capítulo dos chapéus", online. Grifos meus.) Temos aqui um exemplo de sinédoque. Chapéu quer dizer simplesmente "homem" ou "moço". Por que então dizer chapéu? Por que fazer o leitor tomar o caminho mais longo? Nesse caso em particular, Mariana, a protagonista, encontra-se me desacordo com seu esposo, pois gostaria que ele utilizasse um chapéu mais de acordo com sua posição. Assim, o uso da sinédoque não é mero sinônimo prolixo para outra coisa, mas nos relembra da fixação de Mariana com o assunto; ao olhar para os homens passando pela rua, repara inicialmente nos chapéus. Assim, antes de chegarmos ao significado-de-destino, paramos pelo caminho e, por assim dizer, recolhemos passageiros. Através da sinédoque, o narrador obriga o leitor a realizar processos inferenciais que potencializam a capacidade semântica do texto. Seguramente, não tem como controlar quais tipos de inferência ocorrerão, nem garantia de que ocorram. Seja como for, o princípio da escrita indireta literária parece embasado no fato de que não há sinonímia absoluta; o uso ou a forja de sinônimos, mais que substituição, é acréscimo de sentido—ou, mais precisamente, abertura à possibilidade de novos sentidos.

${ }^{\text {vii }}$ A forma $s e . .$. então... foi utilizada na paráfrase para enfatizar sua estrutura causal. O poema não traz if, mas when, o que torna mais segura a afirmação de que (07) e (09) são pressupostas por (06) e (08), respectivamente.

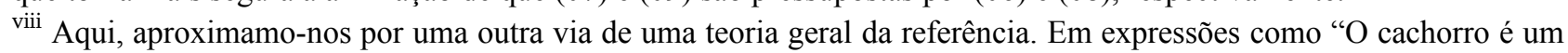
ótimo companheiro", o termo cachorro, apesar de estar no singular e antecedido por um artigo definido, não se refere a qualquer cachorro específico no mundo, mas à classe dos cachorros-diferentemente do que ocorreria se dissesse "Aquele cachorro é um ótimo companheiro". A referência hiperbólica dá um passo além ao equivaler um indivíduo específico a seu conjunto, de modo que uma descrição individual pode ser encarada como uma descrição de classe. É importante atentarmos para o fato de que nossas práticas interpretativas e avaliativas do discurso ficcional pressupõem essa equivalência sujeito-classe: basta haver um único personagem pertencente a qualquer grupo (negros, judeus, imigrantes, índios, homossexuais etc.) em um romance ou filme para que suas críticas discorram a cerca de como retrata aquele grupo: Tia Anastácia e Tio Barnabé não foram interpretados apenas como uma mulher e um homem negros, mas como representações do negro feitas por Monteiro Lobato. 
Certamente, essa associação pode parecer apressada a alguns (e muitas vezes injustamente dolosa ao escritor), justamente porque parece ingênuo vincular firmemente um personagem de constituição complexa a todo um conjunto de indivíduos (que podem ter pouco ou nada em comum alem da característica que os agrupa), embora nada incomum. A saída para esse impasse reside em outros. Em primeiro lugar, no fato de que, como nada disso é explicitado pelo texto literário, essa relação indivíduo-grupo depende do leitor, e portanto nunca é líquida e certa; para o crítico, caberia a tarefa não simples de separar o que seria idiossincrático do personagem como indivíduo da descrição de conjunto que veicula: até que ponto as heroínas de Jane Austen, por exemplo, representam a mulher inglesa da classe média rural inglesa? Até que ponto Elizabeth Bennet é "coletiva"? Quando se torna verdadeiramente "individual"? Dificuldade mais elementar encontrará no labor de selecionar com qual dos muitos possíveis conjuntos deseja lidar: Elizabeth Bennet é uma mulher branca, jovem, solteira, alfabetizada, pertencente à classe média rural; há qual desses conjuntos o exercício crítico enfatizará que representa?

${ }^{\text {ix } U m ~ e p i t a ́ f i o ~ a ̀ ~ M a r q u e s a ~ d e ~ W i n c h e s t e r ~}$

Sob este rico mármore repousa

A que de Winchester era honrosa esposa.

Filha de Visconde, de Conde herdeira;

Mais do que lhe daria a terra inteira:

As belas virtudes de que era ornada,

A seu nobre nascimento somadas. (Minha tradução.)

${ }^{x}$ Não é necessário que essa simulação produza um efeito vívido na audiência. Ninguém morreria afogado ao ouvir uma música que "imitasse" a água_por exemplo, o "Wasserklavier" de Luciano Berio.

${ }^{\text {xi }}$ Para uma abordagem ordenada e direta da crítica ao conceito de arte como imitação, referendo o leitor interessado a REICHER: 2009, pp.148-64.

\section{Referências bibliográficas}

Assis, Machado de. "Capítulo dos chapéus". In: NUPILL: Núcleo de Pesquisas em Informática, Literatura e Lingüistica. <http://www.cce.ufsc.br/ nupill/literatura/capchapeus.html>. Último acesso 22 nov. 2010.

Auden, W. H. "Epitaph on a Tyrant". In: Poets.org, from the Academy of American Poets. $<$ http://www.poets.org/viewmedia.php/prmMID/15548>. Último acesso 22 nov. 2010.

Milton, John. "An Epitaph on the Marchioness of Winchester". In: Luxon, Thomas H. (ed.). The Milton Reading Room. $<$ http://www.dartmouth.edu/ milton/reading_room/marchioness/index.shtml $>$. Último acesso 22 nov. 2010.

Reicher, Maria E. “O que é arte?” In: Introdução à estética filosófica (trad. Monika Otterman). São Paulo: Loyola, 2009. pp.147-97.

SeArle, John. "The logical status of fictional discourse". In: John, Eileen; Lopes, Dominic McIver (orgs). Philosophy of Literature: contemporary and classic readings, an anthology. Blackwell, 2004. pp.112-8. 